\title{
USE OF PRAZIQUANTEL IN POPULATIONS AT RISK OF NEUROCYSTICERCOSIS
}

After our original communications, two further instances of seizures following praziquantel administration during the treatment of intestinal teniasis, became known to the authors (ORIHUELA A., and PLATA O., personal communications). Dr. Orihuela's case, a 39 year-old male with an intestinal infection by $T$. saginata, had previously received a well tolerated, but unsuccessful, 400 $\mathrm{mg} /$ day course of albendazole during 3 days, on account of which, he was later given 50 $\mathrm{mg} / \mathrm{kg} /$ day of PZQ. On the second day of therapy, he experienced several episodes of secondarily generalized right partial seizures. The other patient corresponded to a 45 year-old female that received a single $20 \mathrm{mg} / \mathrm{kg}$ dose of PZQ because of an intestinal hymenolepiasis. Several hours later, she experienced an episode of partial seizure, secondarily generalized. Brain CAT scans in both patients revealed characteristic hypodense cystic lesions of an until then asymptomatic, parenchymal neurocysticercosis, which responded to conventional $15 \mathrm{mg} / \mathrm{kg} / \mathrm{day}$ courses of albendazole during two weeks ${ }^{1}$.

Praziquantel is an acylated isoquinolepyrazine derivative with broad antiparasitic spectrum, used worldwide in both the treatment and control of schistosomiasis ${ }^{6}$, as well as in other trematodes and most cestode infections ${ }^{4}$. Contrary to oxamniquine, another antiparasitic currently utilized in mass chemotherapy programs for the control of schistosomiasis, which is known to cause transient EEG and occasional seizures 2 , praziquantel is devoid of intrinsic neurological toxicity ${ }^{3}$. The two additional cases of praziquantel-associated seizures, mentioned herein, clearly reinforce our initial suggestion that the compound must be administered with caution in those areas where cysticercosis is known to occur. Furthermore, the onset of seizures or other related neurological symptoms in an otherwise healthy individual receiving praziquantel, must prompt exhaustive clinical and laboratory evaluations, including the performance of a CAT scan, in order to rule out brain parenchymal cysticercosis.

Jaime R. TORRES R.

Instituto de Medicina Tropical, Universidad Central de Venezuela, Apartado 2109, Caracas, Venezuela.

\section{REFERENCES}

1. ESCOBEDO, F.; PENAGOS, P. \& RODRIGUEZ, J. - Albendazole therapy for neurocysticercosis. Arch. intern. Med., 147:738-741, 1987.

2. KRAYDEN, S.; KEYSTONE, J. \& GLENN, C. - Safety and toxicity of oxamniquine in the treatment of Schistosoma mansoni infections, with particular reference to electroencephalographic abnormalities. Amer. J. trop. Med. Hyg., 32:1344-1346, 1983.

3. LEOPOLD, G.; BUMRING, K.; DIEKMAN, H.; STEINER, K. \& GRABE, A. - Clinical pharmacology in normal volunteers of praziquantel, a new drug against schistosomes and cestodes. Europ. J. clin. Pharmacol., 14:281-291, 1978.

4. REZENDE, G. - Praziquantel: experiencia clínica mundial. Bol. chil. Parasit., 38: 52-63, 1983.

5. TORRES, J. R.; NOYA, O.; NOYA, B. \& MONDOLFI, A. - Seizures and praziquantel. A case report. Rev. Inst. Med. trop. S. Paulo, 30:433-436, 1988.

6. YOGORE, M.; LEWERT, R. \& BLAS, B. - Seroepidemiology of Schistosoma japonicum by ELISA. III. Selective mass chemotherapy with praziquantel in a control program. Amer. J. trop. Med. Hyg., 35:882$890,1984$.

Recebido para publicação em 1/6/1989 